\title{
Assessment of the spatial variability in tall wheatgrass forage using LANDSAT 8 satellite imagery to delineate potential management zones
}

\author{
Pablo Cicore $\mathbb{1}$ - João Serrano • Shakib Shahidian • \\ Adelia Sousa • José Luis Costa • José Rafael Marques da Silva
}

Received: 29 March 2016 / Accepted: 26 July 2016

(C) Springer International Publishing Switzerland 2016

\begin{abstract}
Little information is available on the degree of within-field variability of potential production of Tall wheatgrass (Thinopyrum ponticum) forage under unirrigated conditions. The aim of this study was to characterize the spatial variability of the accumulated biomass (AB) without nutritional limitations through vegetation indexes, and then use this information to determine potential management zones. A $27-\times-27-m$ grid cell size was chosen and 84 biomass sampling areas (BSA), each $2 \mathrm{~m}^{2}$ in size, were georeferenced. Nitrogen and phosphorus fertilizers were applied after an initial cut at $3 \mathrm{~cm}$ height. At $500{ }^{\circ} \mathrm{C}$ day, the $\mathrm{AB}$ from each sampling area, was
\end{abstract}

P. Cicore $(\bowtie) \cdot$ J. L. Costa

Estación Experimental Agropecuaria Balcarce, Instituto Nacional de Tecnologia Agropecuaria (INTA), Ruta Nacional 226 km 73.5, C.C.276, CP 7620 Balcarce, Buenos Aires, Argentina

e-mail: cicore.pabloleandro@inta.gob.ar

J. Serrano $\cdot$ S. Shahidian $\cdot$ A. Sousa $\cdot$ J. R. M. da Silva Instituto de Ciências Agrárias e Ambientais Mediterrânicas (ICAAM), Escola de Ciências e Tecnologia, University of Évora, Évora, Portugal

J. L. Costa

Faculty of Agricultural Sciences, National University of Mar del Plata (FCA-UNMdP), Balcarce, Argentina

J. R. M. da Silva

Applied Management and Space Centre for Interdisciplinary

Development and Research on Environment (DREAMS), Lisbon, Portugal

A. Sousa · J. R. M. da Silva

Centro de Inovação em Tecnologias de Informação (CITI), Évora, Portugal collected and evaluated. The spatial variability of $\mathrm{AB}$ was estimated more accurately using the Normalized Difference Vegetation Index (NDVI), calculated from LANDSAT 8 images obtained on 24 November 2014 $\left(\mathrm{NDVI}_{\mathrm{nov}}\right)$ and 10 December $_{2014}\left(\mathrm{NDVI}_{\mathrm{dec}}\right)$ because the potential $\mathrm{AB}$ was highly associated with $\mathrm{NDVI}_{\text {nov }}$ and $\mathrm{NDVI}_{\mathrm{dec}}\left(r^{2}=0.85\right.$ and 0.83 , respectively). These models between the potential $\mathrm{AB}$ data and NDVI were evaluated by root mean squared error (RMSE) and relative root mean squared error (RRMSE). This last coefficient was 12 and $15 \%$ for $\mathrm{NDVI}_{\text {nov }}$ and $\mathrm{NDVI}_{\mathrm{dec}}$, respectively. Potential $\mathrm{AB}$ and NDVI spatial correlation were quantified with semivariograms. The spatial dependence of $\mathrm{AB}$ was low. Six classes of NDVI were analyzed for comparison, and two management zones (MZ) were established with them. In order to evaluate if the NDVI method allows us to delimit $M Z$ with different attainable yields, the $A B$ estimated for these $\mathrm{MZ}$ were compared through an ANOVA test. The potential $\mathrm{AB}$ had significant differences among MZ. Based on these findings, it can be concluded that NDVI obtained from LANDSAT 8 images can be reliably used for creating MZ in soils under permanent pastures dominated by Tall wheatgrass.

Keywords Forage yield variability Pasture $\cdot$ Remote sensing $\cdot$ Spectral information $\cdot$ Thinopyrum ponticum

\section{Introduction}

With the advancements in remote detection and use of variable application rate systems, the study of within-field 